\title{
Primary Torsion of the Vermiform Appendix and Undescended Cecum Treated by Video-Assisted Transumbilical Appendectomy
}

\author{
Fernando Montes-Tapia, MD, ${ }^{1}$ Aquiles Quiroga-Garza, MD, ${ }^{2}$ and Valdemar Abrego-Moya, MD, $\mathrm{PhD}{ }^{2}$
}

\begin{abstract}
Torsion of the vermiform appendix is a rare cause of appendicitis that is clinically indistinguishable from the classical presentation. In this paper, we present the first report in the literature of an appendicular torsion associated with an undescended cecum. A 3-year-old male patient with persistent pain in the right hypochondrium and peritoneal irritation underwent diagnostic laparoscopy, finding necrosis of the vermiform appendix caused by torsion of its base associated with an undescended cecum located in an indurated area of the subhepatic region. A video-assisted transumbilical appendectomy was performed.
\end{abstract}

\section{Introduction}

A PPENDICITIS IS THE MOST COMMON CAUSE of abdominal surgery in pediatric patients. ${ }^{1,2}$ Torsion of the vermiform appendix is a rare cause that is clinically indistinguishable from appendicitis. ${ }^{2-8}$ The first description of torsion of the vermiform appendix was made by Payne in $1918 .^{3}$ A lack of elongation of the colon during embryonic development causes the cecum to not descend to the right iliac fossa, which produces an undescended and mobile cecum. ${ }^{9}$

\section{Case Report}

The patient was a 3-year-old male with abdominal colic of 18 hours located in the right flank with hyporexia and vomiting of gastric contents. At the time of the initial evaluation, there were no signs of peritoneal irritation. An abdominal ultrasound was performed without finding the appendix nor signs of inflammation in the right iliac fossa. The patient was reassessed after 18 hours of observation, finding abdominal distension, pain located in the right hypochondrium with a palpable mass, and signs of peritoneal irritation; an abdominal X-ray showed fluid levels. A complete blood count showed leukocytosis $\left(18,500 \mathrm{wbc} / \mathrm{mm}^{3}\right.$ with $95 \%$ neutrophils). A laparoscopic examination was decided because of clinical signs of an acute abdomen.

\section{Surgical technique}

We started with two 5-mm ports, one in the umbilical scar for $5 \mathrm{~mm}$ and 30-degree optics (Karl Storz GmbH \&
Co. KG, Tuttlingen, Germany) and another in the left iliac fossa. On abdominal examination, inflammatory liquid was found in the pelvic cavity and an indurated area in the right parietocolic and subhepatic spaces. We were unsuccessful in an attempt to separate the indurated area, so we placed another 5-mm port in the right iliac fossa. Lysis of adhesions of the omentum, small intestine, and cecum was done. Once the indurated area was separated, we found a necrotic subhepatic appendix, twisted three times counterclockwise, adhered to the abdominal wall of the right parietocolic and subhepatic spaces (Figs. 1 and 2). We also observed that the appendix had a narrow appendicular mesentery and a movable cecum without fixation. A video-assisted transumbilical appendectomy was performed, exteriorizing the appendix and the cecum through the umbilical scar (Fig. 3). The operative time was 55 minutes. Feeding was started on postoperative day 1 , and the patient was discharged on the second day.

\section{Discussion}

Although torsion of the vermiform appendix has been described for 90 years, it is rare in pediatric patients, with 15 cases being reported previously. ${ }^{10,11}$ No specific age predominates, but the range found in the literature varies from 50 days $^{5}$ to adults. ${ }^{12}$ Primary and secondary torsion of the vermiform appendix have been described. Among the primary causes are abnormalities of the mesentery, such as a narrow base, as occurred in our case, the absence of azygotic folds that normally laterally fix the appendix, and even

${ }^{1}$ Department of Pediatric Surgery and 2Pediatric Department, Hospital Universitario “Dr. José E. González," Universidad Autónoma de Nuevo León, Monterrey, México. 


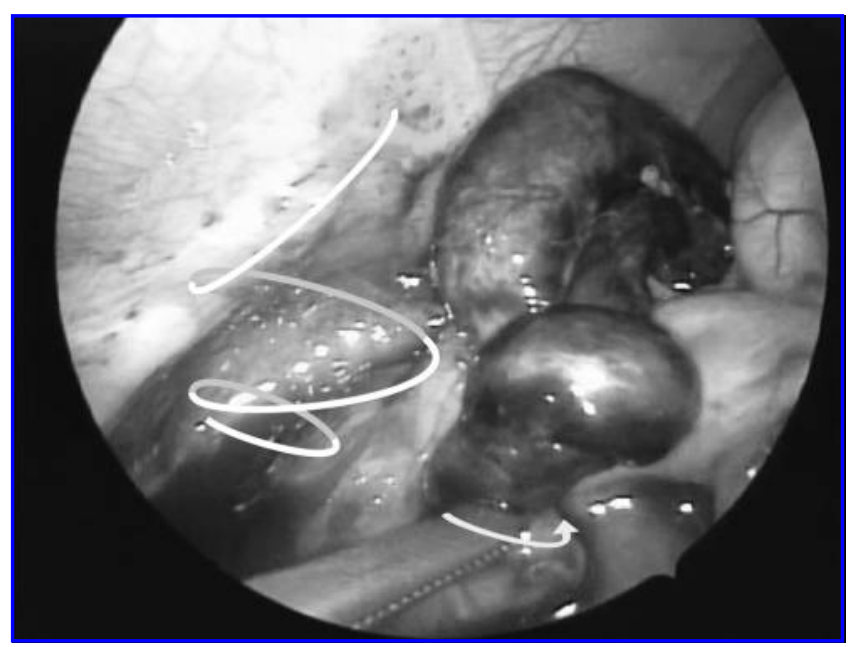

FIG. 1. Arrow at the base of the necrotic appendix indicating counterclockwise torsion. The diagram shows the three turns.

abnormal peristaltic movements. ${ }^{3,4,11}$ Still, its etiology is uncertain. Benign tumor pathology such as mucocele, ${ }^{13}$ malignant pathology such as cistadenoma, ${ }^{11}$ or after intestinal invagination ${ }^{10}$ or intestinal duplication ${ }^{14}$ have been associated to secondary causes.

Abdominal ultrasound has been used to find the vermiform appendix, in the differential diagnosis of the most frequent causes of pain in the right iliac fossa, ${ }^{2,15}$ or to suggest the diagnosis of appendicular torsion. ${ }^{16}$ In our case, the appendix was not found by ultrasound because it was located in the subhepatic area. Computerized tomography has been used for diagnosis in cases where the appendix was not found. ${ }^{11}$

An undescended cecum has been reported in $6 \%$ of the population, predominantly in men. ${ }^{9}$ Cecal malposition

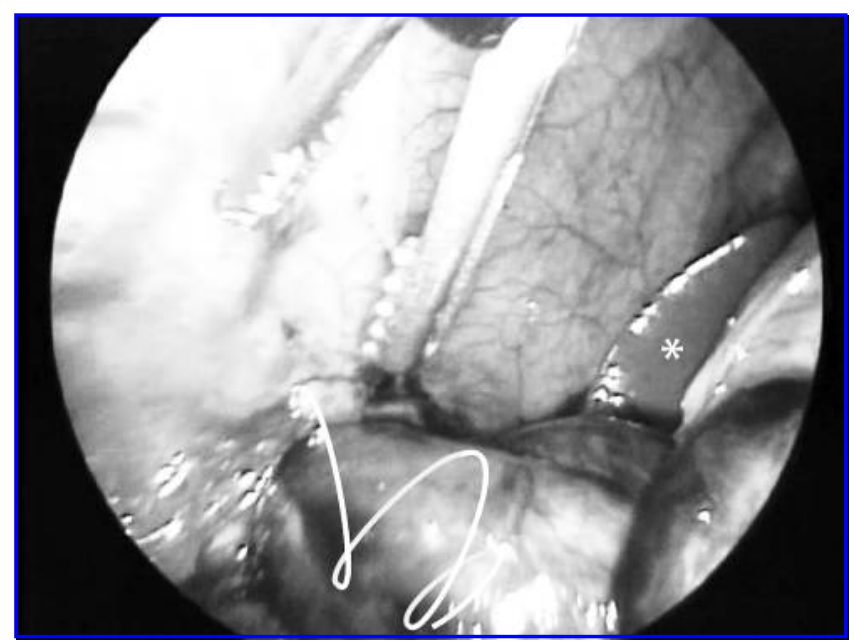

FIG. 2. Diagram of the three turns of appendicular torsion. The asterisk marks the liver, showing the subhepatic location of the appendix and the cecum.

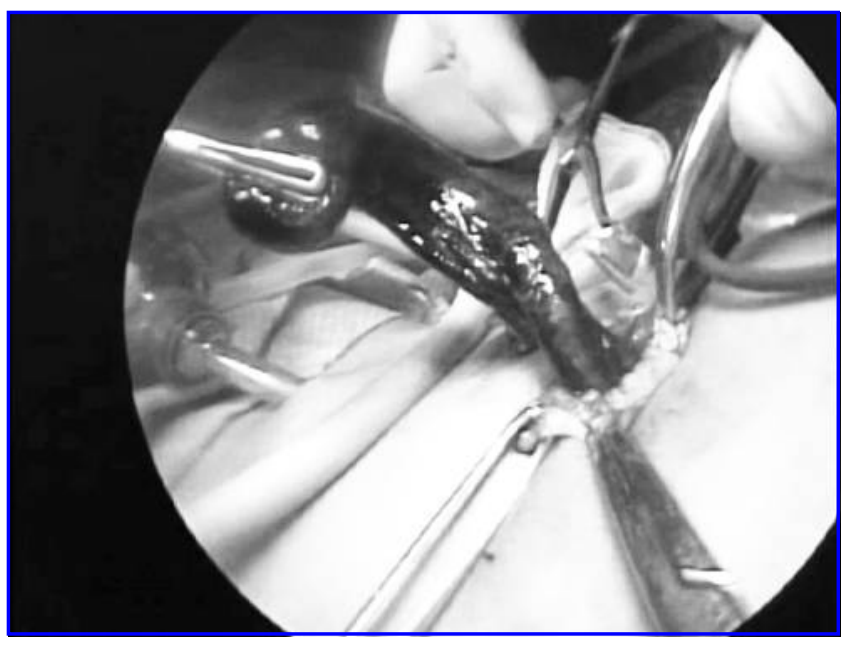

FIG. 3. Extraction of the appendix through the umbilicus for video-assisted transumbilical appendectomy.

makes the clinical diagnosis of appendicitis and appendicular torsion difficult, since abdominal pain is not located in the right iliac fossa. The undescended cecum and its lack of fixation in this case contributed to the torsion of the vermiform appendix and the lack of classical signs of appendicitis.

Surgical treatment in pediatric patients is an appendectomy by the conventional approach or by laparoscopy. ${ }^{17,18}$ A complete laparoscopic appendectomy can also be performed. Our usual approach is the transumbilical video-assisted appendectomy. Since we do not have optics with an operating channel, we usually use two ports to perform a transumbilical video-assisted appendectomy. On this occasion, another port was necessary to separate the indurated area where the necrotic appendix was located. The mobile cecum made the transumbilical appendectomy easier.

\section{Conclusion}

In our patient, laparoscopic exploration led to the diagnosis of acute abdomen caused by appendicular torsion and an undescended mobile cecum. This case is the first report in the literature of this type of association.

\section{Acknowledgements}

The authors thank Sergio Lozano-Rodriguez, MD, for his help in translating the manuscript.

\section{Disclosure Statement}

No competing financial interests exist.

\section{References}

1. Anderson KD, Parry RL. Appendicitis. In: O'Neil JA, Jr, Rowe MI, Grosfeld JL, Fonkalsrud EW, Coran AG, eds., Pediatric Surgery, 5th ed. St. Louis, MO: Mosby, 1998;1369-1379.

2. Rabah R. Pathology of the appendix in children: An institutional experience and review of the literature. Pediatr Radiol 2007;37:15-20. 
3. Dewan PA, Woodward A. Torsion of the vermiform appendix. J Pediatr Surg 1986;21:379.

4. Lowry WL, Redman JF. Torsion of the vermiform appendix: Cause of acutely painful scrotum. Urology 1986;28:117-118.

5. Yeung CK, Saing H. Primary torsion of the vermiform appendix in a 50-day-old infant. Pediatr Surg Int 1991;6: 223-224.

6. Bowling B, Lipscomb G. Torsion of the appendix mimicking ovarian torsion. Obstet Gynecol 2006;107:466-467.

7. Bestman TJR, van Cleemput M, Detournay G. Torsion of the vermiform appendix: A case report. Acta Chir Belg 2006;106: 228-229.

8. Sarin YK, Pathak D. Torsion of vermiform appendix. Ind Pediatr 2006;43:266-267.

9. Skandalakis JE, Gray SW, Ricketts R, Richardson DD. The small intestines. In: Skandalakis JE, Gray SW, eds. Embryology for Surgeons, 2nd ed. Baltimore, MD: William \& Wilkins, 1994;184-241.

10. Baeza-Herrera C, García-Cabello LM, León-Cruz A, Martínez-Rivera ML. Torsión del apéndice cecal asociada a invaginación intestinal [Torsion of the cecal appendix associated with intestinal invagination]. Cir Ciruj 2006;74:369371.

11. Kitagawa $M$, Kotani $T$, Yamano $T$, Tsurudome $H$, Hatakeyama T, Kuriu Y, Nishi H, Yabea M. Secondary torsion of vermiform appendix with mucinous cystadenoma. Case Rep Gastroenterol 2007;1:32-37.

12. Tzilinis A, Vahedi MH, Wittenborn WS. Appendiceal torsion in an adult: Case report and review of the literature. Curr Surg 2002;59:410-411.
13. Udo R, Sandeep M. Volvulus of an appendiceal mucocele: Report of a case. Surg Today 2007;37:514-517.

14. Oguzkurt P, Oguzkurt L, Kayaselcuk F, Oz S. An unusual cause of acute abdomen: Torsion of colonic duplication over a duplicated appendix. Pediatr Surg Int 2004;20:722723.

15. Abu-Yousef MM. Ultrasonography of the right-lower quadrant. Ultrasound Q 2001;17:211-225.

16. Uroz-Tristan J, García-Urgelles X, Poenaru D, Avila-Suarez $\mathrm{R}$, Valenciano-Fuentes B. Torsión of vermiform appendix: Value of ultrasonographic findings. Eur J Pediatr Surg 1998;8:376-377.

17. Gopal K, Kumar S, Grewal H. Torsion of the vermiform appendix. J Pediatr Surg 2005;40:446-447.

18. Koontz CS, Smith LA, Burkholder HC, Higdon K, Aderhold $\mathrm{R}$, Carr R. Video-assisted transumbilical appendectomy in children. J Pediatr Surg 2006;41:710-712.

Address correspondence to: Fernando Montes-Tapia, MD Department of Pediatric Surgery Hospital Universitario "Dr. José E. González" Universidad Autónoma de Nuevo León Madero y Gonzalitos s/n, Monterrey Nuevo León 64460 México

E-mail: ffmt@yahoo.com 
